\title{
O DIREITO E AS CIDADES INTELIGENTES: DESAFIOS E POSSIBILIDADES NA CONSTRUÇÃO DE POLÍTICAS PÚBLICAS DE PLANEJAMENTO, GESTÃO E DISCIPLINA URBANÍSTICA
}

\section{LAW AND SMART CITIES: CHALLENGES AND POSSIBILITIES IN THE CONSTRUCTION OF PUBLIC POLICIES FOR URBAN PLANNING, MANAGEMENT AND DISCIPLINE}

\author{
Janriê Rodrigues Reck ${ }^{1}$ \\ Fábio Scopel Vanin ${ }^{2}$
}

Resumo: O trabalho tem como objetivo observar se a tecnologia empregada nas políticas públicas de cidades inteligentes é suficiente para tornar obsoleto os instrumentos jurídicos tradicionais de planejamento, gestão e disciplina da atividade urbanística. Para isso, se apresentam algumas descrições sobre as Smart Cities, observam-se os instrumentos jurídicos tradicionais e como as novas tecnologias tem sido utilizadas para o exercício das políticas públicas de planejamento, gestão e disciplina, para ao final, apresentar reflexões jurídicas sobre o tema. Como conclusão, verifica-se que a utilização dos novos mecanismos tecnológicos tem servido de apoio e não para substituição dos instrumentos existentes, com a ressalva da tecnologia ser um tema em aberto, dinâmico e de resultados imprevisíveis, inclusive seu próprio uso como apoio pode ser suficientemente capaz de substituir os instrumentos jurídicos existentes. $O$ trabalho vale-se do método de procedimento estruturalista, com reflexões baseadas na matriz teórica sistêmica.

Palavras-Chave: Cidades Inteligentes. Políticas Públicas. Instrumentos Jurídicos. Teoria dos Sistemas. Planejamento Urbano.

Abstract: The research objective is to observe if the technology employed in the public policies of intelligent cities is sufficient to render obsolete the traditional legal instruments of planning, management and discipline of the urban activity. For this, some descriptions about the Smart Cities are presented, will be observed the traditional legal instruments and how the new technologies have been used for the exercise of the public policies of planning, management and discipline, in order to present legal reflections on the subject. As a conclusion, the use of new technological mechanisms has served as a support and not as a substitute for existing instruments, with the exception of technology being an open, dynamic and unpredictable subject, including its own use as support sufficiently capable of replacing existing legal instruments. The work is based on the method of structuralist procedure, with reflections based on the theoretical systemic matrix.

Keywords: Smart Cities. Public policy. Legal Instruments. Theory of Systems. Urban planning.

\footnotetext{
${ }^{1}$ Doutor em Direito. Professor do Programa de Pós-Graduação em Direito da Universidade de Santa Cruz do Sul. Procurador Federal. Universidade de Santa Cruz do Sul. Brasil. E-mail: janriereck@ibest.com.br

2 Doutorando em Direito pela UNISC e Mestre em Direito pela Universidade de Caxias do Sul. Possui MBA em Direito pela FGV/RJ e Cursos de Desenvolvimento Profissional pelo Lincoln Institute, Cambridge/EUA. Centro Universitário da Serra Gaúcha. Brasil. E-mail: fabiovanin@terra.com.br
} 


\section{Introdução}

A forma de utilizar a informação tem sido um dos pontos de maior relevância para o desenvolvimento da economia com enfoque tecnológico. Termos como era da informação, indústria 4.0, nova indústria, entre tantos outros, tem sido utilizados para simbolizar e explicar a relação do ser humano com o vasto repertório de TICs (Tecnologia de Informação e comunicação) que tem como finalidade tornar a vida das pessoas mais práticas, a partir de uma otimização da vasta informação disponível para a tomada de decisão.

A questão não é diferente nas cidades: as Smart Cities ou Cidades Inteligentes são uma realidade cada vez mais presente, tendo se tornado mais uma das pautas dos governos locais, com o objetivo de tornar mais eficientes os serviços públicos prestados, assim como, melhorar os índices de desenvolvimento socioeconômico e ambiental, melhorando a vida das pessoas nas cidades. As opções transpassam as mais diferentes áreas, sendo apresentadas soluções para gestão pública da saúde, meio ambiente, mobilidade urbana, turismo, lazer, assim como, para o planejamento, gestão e disciplina das atividades urbanísticas.

Neste cenário, se faz o seguinte questionamento: Os mecanismos tecnológicos que caracterizam as novas Políticas Públicas para cidades inteligentes tornam obsoletos os tradicionais instrumentos jurídicos de planejamento, gestão e disciplina urbanística? A pergunta se justifica em decorrências das facilidades anunciadas por estes novos mecanismos, que tendem a estar muito mais aptos a lidar com a contingência e complexidade que caracteriza a sociedade moderna.

Para o enfrentamento do problema, o trabalho apresenta algumas descrições sobre as Cidades Inteligentes, indica quais seriam os instrumentos tradicionais e como a tecnologia auxilia o exercício de suas atividades, com a apresentação de alguns desafios, para ao final, responder o problema proposto. Parte-se da hipótese de que as tecnologias não substituem os instrumentos jurídicos tradicionais, mas tendem a modificar o seu processo e possibilitando maior efetividade.

O trabalho é construído tomando por base os conceitos da teoria dos sistemas no desenvolvimento de suas reflexões, em especial, para definir políticas públicas, seu regime jurídico e implicações, a partir das distinções e interações do sistema do direito e do sistema da política, a fim de garantir rigor cientifico para o ensaio. A partir da teoria dos sistemas e da complexidade foi possível compreender as interconexões entre Direito, tecnologia e urbanismo. Como resultado, pretende contribuir no avanço dos estudos jurídicos sobre cidades inteligentes no Brasil, em especial, quanto aplicação dos instrumentos de planejamento, disciplina e gestão da atividade 
urbanística, previstos na Constituição Federal, Estatuto da Cidade, da Metrópole e outras normas correlatas.

\section{Algumas Descrições Necessárias sobre as Cidades Inteligentes}

Os estudos que abordam o tema das Smart Cities tem sido recorrentes em afirmar que se trata de um conceito em construção, entretanto, já é possível observar um certo consenso, no sentido de que as ações com esta finalidade devem envolver o uso de tecnologia com enfoque nas pessoas e com o objetivo de proporcionar melhorias socioambientais e econômicas para as comunidades locais, abarcando um leque de soluções que transpassam os mais diferentes serviços públicos setoriais. Outro ponto apresentado pelas pesquisas é que as Cidades Inteligentes são mais um resultado evidente do que se denomina indústria 4.0, era da informação, entre outros conceitos, sendo um fenômeno em franca ascensão e que gera resultados e mudanças significativas em inúmeras áreas, inclusive, sobre os instrumentos jurídicos para políticas públicas de urbanismo.

A observação de um enfoque industrial voltado a informação, que gera impacto nas cidades, aparece muito bem descrito na obra as "Tecnópolis del Mundo", onde Castells e Hall (2001, p. 13) destacam este novo tempo com a seguinte analogia: enquanto os avanços do Século XIX, era da industrialização, foram simbolizados por imagens como "la mina de carbón y la fundición de hierro vecina, vomitando humo negro al firmamento e iluminando los cielos nocturno con brillante fulgor rojo", o processo em andamento, denominado como "nova economia" e que teve início no final do século XX, tem como símbolo "un conjunto de edificios discretos e bajos, que habitualmente desprenden un cierto aire de buen gusto y que están situados en unos parajes impecables", representdo uma atmosfera no estilo de campus universitários ${ }^{3}$.

Ao falar em Tecnópolis, os autores não trabalham as Smart Cities na forma como hoje elas são observadas, mas da indústria que moveu toda essa mudança. Tais parques industriais se desenvolvem com a criação de novas estruturas e espaços, em alguns casos equiparados com novas cidades ou grandes projetos de edificação e urbanização planejados, muitas vezes decorrentes de cooperação público e privada, contando com a participação universidades e do diálogo e

\footnotetext{
${ }^{3}$ Complementando sua ideia, Castells e Hall (2011, p. 19-20) destacam que cenas como as descritas são frequentes em toda a zona urbana dinâmica do mundo. Como exemplos, cita as cidades Cambridge, tanto na Inglaterra, quanto nos EUA'; Montain View, na Califórnia; Munich, na Alemanha. Todos eles recebem uma variedade de nomes baseados em elementos chaves, como tecno, ciência, século XXI, parque, praça, cidade, entre outros.
} 
investimento de governos de diferentes níveis federativos. A função da Tecnóplis não é a mesma da cidade, mas sim desta nova indústria. Segundo Castells e Hall (2011, p. 20) a finalidade destes ambientes é "generar los materiales básicos de la economia de la información".

Tratar de Cidades Inteligentes não é, necessariamente, falar das Tecnópolis. Ao mesmo tempo, deve se ter clareza, que as primeiras são resultado do fenômeno das segundas. Para Castells e Hall (2011, p. 21-22) o surgimento das Tecnópolis evidenciam uma nova realidade urbana: de que as cidades e as regiões metropolitanas estão sendo profundamente modificadas por três grandes processos históricos, que são totalmente inter-relacionados: (1) uma revolução tecnológica, que é tão significativa quando a revolução industrial; (2) a formação de uma economia global, que torna cada vez mais evidente um mercado sem fronteiras, que antes era demarcado pelos governos nacionais; (3) uma nova forma de produção e de gestão da economia, baseado na criação de novos conhecimentos no processamento da informação de forma adequada.

Assim, embora a proposta dos autores não seja estudar as Cidades Inteligentes, na forma como o conceito vem sendo trabalhado e será abordado neste trabalho, que toma em conta a aplicação de tecnologia nas comunidades locais, a observação das ideias de Castells e Hall (2011, p. 31) sobre as Tecnópolis é fundamental para compreender o processo onde este fenômeno está inserida a cidade intelifentes: "Ios medios industriales innovadores que conducen a un crecimiento económico regional o local verdaderamente dinámico". A ideia de Smart Cities é, grosso modo, um resultado do trabalho que ocorre em "Ios diversos tipos de medio innovador que podemos encontrar realmente en mundo actual" naqueles espaços de concentração territorial de inovação tecnológica, que baseiam-se na lógica de uma interação da "sinergia científica y una productividad económica"4.

Quando se observam as políticas públicas para Cidades Inteligentes, que possuem, em regra, um enfoque finalístico voltado para as melhoria dos serviços públicos prestados pelas comunidades locais, para a melhorias da vida dos cidadãos, percebe-se sua inserção em um plano maior, onde há uma preocupação constante dos governos nacionais em alavancar sua indústria da informação, ou seja, desenvolver Tecnópolis. A Espanha, país que já possui um Plano Nacional voltado para Smartie Cities, deixa isso muito claro quando esclarece qual é o objetivo central da proposta: "el objetivo último del Plan de Ciudades Inteligentes es contribuir al desarrollo económico". Assim, a aplicação do programa de Cidades Inteligentes no país europeu visa maximizar o uso do TIC nas gestões locais "para mejorar la productividad y la competitividad, y

\footnotetext{
${ }^{4} \mathrm{Na}$ obra, os autores analisam experiências como o Vale do Silício, na Califórnia; Boston 128; Parques Tecnológicos e Cidades da Ciência; Programa Tecnópolis, Japão, entre outros.
} 
transformar y modernizar la economía y sociedad española". (ESPANHA, 2015, p.16). Evidentemente que se trata de viés que coloca a economia no centro, e não a pessoa. Entretanto, é claro que o ideário das smart cities pode ser incorporado às funções sociais da cidade.

O Brasil ainda não possui um plano específico para Cidades Inteligentes, entretanto, sua Estratégia Nacional de Ciência, Tecnologia e Inovação (2017, p. 63-64), que faz algumas menções para o tema, também tem como foco central o desenvolvimento desta indústria, vez que entre os desafios nacionais apontados encontram-se "aprimorar as condições institucionais para elevar a produtividade a partir da inovação" e posicionar o Brasil entre os países com maior desenvolvimento na área. As políticas nacionais apresentadas são um forte indicativo que o apoio para as Políticas Públicas para Smart Cities trazem consigo uma preocupação com a novo modelo industrial, como destacado na abordagem de Castells e Hall (2011) sobre as Técnópolis, reforçando a distinção e a interligação entre os temas.

O desenvolvimento da nova indústria, traz consigo, entre outros desdobramentos, uma série de melhorias aplicáveis para as cidades, em especial, para as políticas públicas voltadas ao urbanismo. Rubio (2009, p. 101) vê uma evidente relação entre as atividades urbanísticas e as novas tecnologias, existindo vários pontos de conexão entre as atividade dela decorrente e "el prolífico mundo de las TICs". O autor destaca ainda que o "urbanismo como ciencia que se ocupa de la regulación y habitabilidad del entorno humano es absolutamente permeable al fenómeno imparable de las nuevas tecnologías de la comunicación y la información".

Diversas novas tecnologia tem sido apresentadas como alternativas na melhoria da prestação dos serviços públicos urbanos: aplicativos que facilitam problemas cotidianos como a falta de vagas de estacionamento na cidade; que indicam o tempo de demora do transporte coletivo; possibilidade de petição eletrônica perante órgãos públicos; superação de dificuldade e custo de locomoção com a oferta de modais alternativos como bicicletas, patinetes e carros elétricos; possibilidade de participação em consultas públicas sobre a mudanças em políticas públicas por meio de fóruns digitais; entre outros tantos exemplos que se disseminam no dia.

Dentro deste novo universo de posibilidades, percepções como as de Tejeda (2015, p. 15) consideram as Smartie Cities como a resposta de "cómo las ciudades y las áreas metropolitanas que las rodean pueden evolucionar hacia un desarrollo abierto, sostenible y cuya pieza clave sea el ciudadano". Na opinião de Rubio (2009, p. 101) não se demostra aceitável pensar a cidade "sin tener em cuenta la multitud de servicios que la sociedad de la información y las telecomunicaciones 
ofrecen a los ciudadanos" através de tecnologías como WI-FI, ADSL, televisão digital, telefonía móvel, que devem ser contempladas nas instalações urbanas.

Tais reflexões de Tejeda (2015) e Rubio (2009) remetem ao problema central desta pesquisa: se cada vez mais a tecnologia nas cidades é vista como um caminho sem volta, tornandose impensável o exercício das atividades municipais sem a utilização de TICs ou outras alternativas consideradas inteligentes, em que situação ficam os mecanismos jurídicos tracionais de urbanismo? Permanecem como algo importante ou tornam-se obsoletos? Parte-se da hipótese de que as tecnologias não substituem os instrumentos jurídicos tradicionais, mas tendem a modificar o seu processo e possibilitando maior efetividade.

A utilização da tecnologia para melhorias das atividades urbanas demonstra-se como um tema relevante, tendo recebido atenção nos debates internacionais. A ONU, através na Nova Agenda Urbana (2016), documento decorrente dos debates que guiaram a Agenda Habitat III, incluiu no relatório o tópico $66^{5}$, que aponta para a observação do tema nas ações de desenvolvimento urbano. Além disso, há um caderno específico das Nações Unidas, decorrente dos debates prévios na formação da Nova Agenda Urbana que trata das Cidades Inteligentes. Em seu texto são destacadas algumas diretrizes relacionadas ao exercício de políticas públicas com enfoque nas atividades urbanísticas, sendo destacado ser necessária uma "abordagem alavancando novos conhecimentos e ferramentas para promover planejamento e desenho urbanos que atendam à evolução das necessidades e desafios da urbanização" e considera a cidade inteligente como uma opção viável para o futuro (ONU, 2015, p. 2-3).

Embora o tema das Smart Cities já abarque uma série de estudos nas últimas décadas e consolida-se como uma pauta internacional, verifica-se uma quantidade reduzidas de produção científica em Direito, em especial no Brasil, que tenha como enfoque os instrumentos jurídicos para a atividade urbanística. A maioria dos trabalhos tem trazido questões conceituais e avaliado experiências de alguns municípios, o que tem contribuído para o avanço do tema, que ainda carece de maiores especificações.

Alguns exemplos de estudos são os promovidos por Guimarães e Xavier (2016), que trata dos aspectos conceituais e da relação geral do Direito; Guimarães e Araujo (2018), que trata as

\footnotetext{
5 "66. Comprometemo-nos a adotar uma abordagem de "cidade inteligente", que faça uso de oportunidades de digitalização, energia e tecnologias limpas, assim como de tecnologias de transporte inovadoras, proporcionando consequentemente alternativas para os habitantes tomarem escolhas mais amigáveis ao ambiente e impulsionarem o crescimento económico sustentável, permitindo que as cidades melhorem a sua prestação de serviços".
} 
Smartie Cities na perspectiva do Direito à Cidade, trazendo a experiência de alguns municípios; Staparazzon (2009), que trata das possibilidades de adoção destas políticas em municípios médios e pequenos; Nabuco, Macedo e Ferreira (2009), trabalhando a participação digital em Belo Horizonte, e ainda, Piekas, Bernardy, Sehnem e Fabris (2018), que observam aspectos legais das Cidades Inteligentes em Chapecó.

Valendo-se da experiência da Espanha no tema, agora em estudos no âmbito do Direito, a obra de Mañas e Ojeda (2017) traz uma série de estudos sobre o tema, com enfoque em questões de participação pública, sigilo de dados individuais, meio ambiente, planejamento urbano, desafios do direito público e acessibilidade. Na sua apresentação é destacado que o livro "viene a cubrir un significativo hueco en los estúdios sobre smart cities" que é apresentado como "una temática extraordinariamente novedosa que exigirá un esfuerzo importante de todos los operadores para conseguir integrar con eficacia" os novos desafios tecnológicos e jurídicos que surgem nas cidades. Tais ponderações demonstram que a questão também é incipiente, se tomado como base o direito comparado.

Importante delimitar que o presente estudo tem como enfoque uma abordagem pontual: a relação entre a tecnologia e os instrumentos jurídicos que tratam das políticas públicas de atividade urbanística. Com base nos estudos de Rubio (2009, p. 101), pode-se organizar o tema a partir de três âmbitos clássicos do urbanismo: o planejamento, a gestão e a disciplina urbanística. É com base nestas três atividades que se procederá a organização na abordagem do trabalho. Em um primeiro momento serão apresentados os principais instrumentos previstos no direito brasileiro e que objetivam planejar, gerir e disciplinar as atividades urbanas. Em seguida, relacionálos com as tecnologias que tem sido aplicadas as Smart Cities. Por último, serão apresentadas as reflexões, a fim de confirmar ou refutar a hipótese, propondo uma resposta ao problema proposto.

Para realização deste trabalho, será tomado repertório conceitual da teoria dos sistemas como elemento central no desenvolvimento das reflexões, sendo observada também a programação do direito brasileiro, em especial a Constituição Federal, o Estatuto da Cidade e as diretrizes gerais da legislação municipal, como forma de indicar quais são os instrumentos jurídicos tradicionais e sua relação com a tecnologia. A preocupação permanente do ensaio é observar se uso das tecnologias exclui ou inclui instrumentos jurídicos como Plano Diretor, Lei de Parcelamento do Solo, Código de Obras e de Posturas, e ainda, algumas atribuições práticas, como a aprovação de projetos arquitetônicos e do parcelamento do solo. 
Um dos pontos chaves no avanço da pesquisa é explicar o que se entende e quais são os instrumentos jurídicos tradicionais para a promoção de políticas públicas de atividade urbanística. Para isso é de fundamental importância compreender as possíveis comunicações entre o sistema do Direito e o sistema da Política. A explicação irá valer-se de conceitos da teoria dos sistemas, em especial, a compreensão das funções de cada sistema e a possibilidade de ocorrer um acoplamento de suas comunicações em determinados casos, como observado no tópico a seguir.

\section{Os Instrumentos Jurídicos e as Políticas Públicas de Planejamento, Gestão e Disciplina Urbanística}

Apresentados alguns aspectos gerais que caracterizam o processo que trouxe o tema das tecnologias para o centro do debate do desenvolvimento urbano, assim como, algumas características e ações relacionadas as Smart Cities, cabe agora apresentar os principais instrumentos jurídicos que regulamentam as políticas públicas urbanísticas. $O$ tópico é estruturado em duas partes: na primeira, será apresentada a relação entre o Direito e a Política, com o objetivo de garantir certo rigor teórico nas distinções e comunicação entre o direito e a política, mais precisamente, os instrumentos jurídicos e as políticas públicas. Em seguida, com base na classificação de planejamento, gestão e disciplina, serão apresentados os instrumentos tradicionais previstos no direito brasileiro.

O direito e a política possuem uma conexão muito próxima. Luhmann (2016, p. 546) aponta a existência de uma tradição que nos remete "a ver apenas um sistema político-jurídico unificado", em especial, pela existência de um "conceito de Estado, que é a um só tempo jurídico e político". Tomado por base as reflexões do autor em termos contemporâneos, pode-se dizer que "a positivação do direito e a democratização da política apoiam-se reciprocamente, tornando-se difícil perceber aí dois sistemas diferentes, e, mais ainda, dois sistemas livres de coincidências em sua operação"6 (LUHMANN, 2016, p. 558). Apesar destas similaridade, Luhmann (2016, p. 559) reforça que na perspectiva sistêmica "não se trata de um sistema único e passível de ser caracterizado com o conceito de Estado, mas de dois sistemas diversos, cada qual fechado com sua operação, com suas respectivas formas, codificações e programas".

\footnotetext{
${ }^{6}$ Complementando este entendimento, Luhmann (2016, p. 558) aponta que "na realidade, a tese da unidade (entre política e direito) jamais foi levada até o ponto em que se dissesse que o que é permitido juridicamente na política determina-se exclusivamente do ponto de vista da política; tampouco se pode dizer que o direito não é mais do que um momento da inércia própria da política, que serve para que a política não ceda a caprichos demasiados passageiros".
} 
Tomando-se como base a teoria dos sistemas, o sistema do direito e o sistema da política possuem códigos e funções distintas. O código e a função são características permanentes dos sistemas, que diferenciam um sistema dos demais. Ao tratar do sistema do Direito, Luhmann (2016, p. 81) explica que "só mesmo estas duas aquisições, função e código, tomadas em conjunto, atuam de modo a fazer com que as operações específicas do direito se diferenciem claramente de outras comunicações", e esta afirmação pode também valer para a política. $O$ direito opera a partir de um código binário direito/não direito, ao contrário da política, que tem como código governar/não governar. Para o autor "no sistema jurídico não há equivalente à codificação democrática de poder no esquema governo e oposição", mas sim, uma codificação que vai dizer o que é direito e o que não é direito. (LUHMANN, 2016, p. 564).

Da mesma forma que os sistemas respondem para códigos distintos, eles possuirão funções próprias. Conforme expõe Reck (2018, p. 57) "as funções não tem um "porquê"”", sendo "fruto de uma evolução". Enquanto o sistema do direito tem como funcionalidade estabilizar expectativas normativas, a função do sistema da política é produzir decisões vinculantes a toda a sociedade. Neste sentido, cada um dos sistemas funcionam a partir de uma lógica (código e funções próprias), o que torna, como bem refere Luhmann (2016, p. 569) "completamente possível pensar que o sistema político decida de maneira involuntária contra o direito - ou que - isso ocorre com frequência - algo seja posto em risco juridicamente" quando ocorre uma decisão política. Ademais, o autor destaca que "o risco é um bom indicador de que se está ultrapassando os limites do sistema".

Trazendo estas reflexões para o estudo em concreto, verifica-se que os instrumentos jurídicos urbanísticos, na perspectiva do sistema do direito, servem como programas para aferição do código Direito ou não Direito, tendo como função estabilizar expectativas normativas. Em outras palavras, o sistema do direito funciona com o objetivo de gerar expectativas que o uso dos instrumentos jurídicos, nos termos previstos na legislação e jurisprudência (programação) será algo estável, estando de acordo com o próprio sistema e não gerando questionamentos ou contestação judicial. Já, na perspectiva da política, não é uma possível estabilidade e compatibilidade com o direito que interessa, mas sim se a decisão vincula e como será observada pelo código governo/oposição.

Para Luhmann (2016, p. 568) "não se segue, a partir da função do sistema da político do decidir juridicamente vinculativo, que a decisão seja conforme ao direito ou contrária a ele". Tal observação até pode ser prévia, como medida de cautela, como frequentemente acontece na 
tomada de decisão política. Entretanto, ao fim, o sistema da política irá observar os instrumentos jurídicos como oportunidade de cumprir sua função, que é gerar decisões vinculantes para toda a sociedade e observará esta decisão com base no seu código, governo e não governo. Estas decisões, em conjunto, podem configurar-se em uma Política Pública.

Destacadas as distinções no modo de observação e operação dos sistemas, para que se avance, se faz necessário apontar se há possibilidade de relações causais entre os sistemas do direito e o sistema da política, em especial para tratar dos instrumentos jurídicos e das políticas públicas urbanísticas. Apesar dos elementos diferenciadores entre os sistemas, destacados até aqui, Luhmann (2016, p. 104) ao tratar do sistema do direito, afirma que ele opera de uma maneira "normativamente fechada", mas "cognitivamente aberta". Assim, a teoria dos sistemas, ao mesmo tempo que define uma identidade própria para cada campo, reconhece que há possiblidades de abertura e de comunicação. Isto quer dizer que, embora ambos sistemas possuam um código e uma função próprios e perenes, há possiblidade de comunicação de cada um deles com o ambiente (onde está o outro sistema) a partir da chamada abertura cognitiva. Tais comunicações podem ser, inclusive, simultâneas, o que ocorre em decorrência dos acoplamentos operativos, conceito que auxilia na compreensão do que seriam Políticas Públicas.

Com base no conceito de acoplamento operativo, Luhmann (2016, p. 590) explica ser possível que eventos sejam observados de maneira simultânea entre o sistema e o ambiente ${ }^{7}$ e tais situações somente permanecem enquanto durar determinado evento. Aduz ainda o autor que tais acontecimentos são caracterizados de uma certa ambiguidade, devendo ser observada sempre dentro de uma rede recursiva. Tal conceito é fundamental para que se entenda como as políticas públicas se apresentam como decisão simultânea, a ser observada e gerar eventos subsequentes tanto no sistema do direito, quanto da política.

Valendo-se do conceito de Reck (2018a, p. 118) "política pública é uma unidade de decisões políticas/jurídicas" que visa a "articulação de instrumentos esparsos" garantindo que determinadas finalidades sejam alcançados. Conforme explica o autor "sem a política pública, o uso dos instrumentos pela Administração Pública fica desconectado de uma linha de objetivos". Desta forma, pode-se compreender que uma política pública decorre de um acoplamento operativo, que pode ser observado a partir de finalidades diferentes, qual seja, decisões que produzirão decisões

\footnotetext{
${ }^{7}$ Aqui deve se destacar que tudo aquilo que não é sistema é considerado ambiente. Assim, para o sistema do direito, o sistema da política faz parte do ambiente, da mesa a forma o direito quando observado a partirda política.
} 
vinculantes para toda a sociedade (sistema da política), assim como, um programa que visa estabilizar expectativas normativas (sistema do direito). A política pública, assim, congregará instrumentos clássicos do Direito Administrativo, como a obra pública, o serviço público, o poder de polícia, em direção a objetivos determinados. Durante o ciclo da política pública diversas decisões são tomadas. Há se de pensar no que estas decisões e estes instrumentos, em matéria urbanística, são afetados pela 4⿳亠丷冖 revolução industrial.

Tal observação se torna ainda mais clara e relevante da perspectiva do regime jurídico das políticas públicas. Para Reck (2018a, p. 127-128) regime jurídico significa um conjunto de operações predeterminadas, que liga programas condicionais e finalísticos ${ }^{8}$. Um exemplo de programa geral do regime jurídico é o princípio da legalidade. Os autores Mateo e Sanchez (2012, p. 75), contribuem com a presente explicação ao fazerem a seguinte afirmação "lo que sucede es que la Administración está tan próxima al interés público, tiene el bien general tan presente, que ello la puede hacer abandonar los caminos estrictamente legales".

O conteúdo na programação do direito não é o único elemento que define a atuação última da administração pública e consequentemente, as políticas públicas. As políticas públicas representam um acoplamento operativos de dois sistemas, que possuem funções diferentes, e como já dito, decorrerão de decisões, muitas vezes tomadas em um ambiente de risco. A legalidade é um parâmetro essencial: segundo Reck (2108a, p. 129) "boa parte dos instrumentos de uma política pública necessita de lei no quadro do Direito Administrativo brasileiro", assim como a "criação de órgãos públicos, a contratação de servidores públicos, o regramento dos serviços públicos, entre outros, são matérias que demandam legalidade estrita". Embora seja um parâmetro essencial, ele não terá uma observância idêntica nos dois sistemas, tornando-se ainda mais complexo quando observado em um cenário de políticas públicas, que caracteriza um acoplamento operativo.

Exemplo disso é que, uma política pública que visar integrar tecnologia as atividades urbanísticas tende vincular a sociedade desde sua criação, podendo ser aceita, bem avaliada e cumprida pelos habitantes, isto tudo na perspectiva do sistema da política. Pelo sistema do direito, ela poderá ser considerada em desacordo com sua programação, em decorrência da observação realizada pelos mecanismos de controle, como concluem Mateo e Sanchez $(2012$, p. 75$)$ ao seguir em sua reflexão sobre a legalidade e o interesse público: "de aqui, que intervegnan otros órgonos

\footnotetext{
${ }^{8} \mathrm{~A}$ distinção entre programas finalísticos e condicionais é aprofundada no último tópico.
} 
imparciales para revisar la actuación de los órganos administrativos, para evitar que su versión del interés público sea distinto de que se recoge por el legislador".

Quando o controle for judicial ou administrativo, inclusive tendo como base a autotutela ${ }^{9}$ ele deve basear-se na estrutura e na programação do Direito, observando o passado. A programação do direito é que vai indicar se a decisão está de acordo, tendo na constituição seu elemento central. O texto constitucional é considerado como o local onde se acoplam estruturalmente estes os sistema do direito e da política. Para Luhmann (2016, p. 641) "a Constituição provê soluções políticas para o problema da autorreferência do direito e soluções jurídicas para o problema da autorreferência da política", sendo para o direito "uma lei suprema, uma lei fundamental", e para a política "um instrumento político no duplo sentido de política instrumental (modificadora de decisões) e de política simbólica (modificadora de situações).

Observar sistemicamente as políticas públicas é ter noção de que suas decisões representam um acoplamento operativo, e que, seu conteúdo tem como elemento central a Constituição, que é um acoplamento estrutural dos dois sistemas. Nesta perspectiva, observar os instrumentos jurídicos que regulamentam a ação do Estado no exercício de atividades urbanísticas, acaba por significar observar suas políticas públicas, e sendo assim, a visualização pode ser feita tanto na perspectiva do direito, quanto da política, a partir de sua recursividade própria.

A Constituição Federal, como lei suprema para o direito e instrumento político de modificação de decisões e de situações para a política é quem traz consigo as bases para o exercício das atividades urbanísticas pelo Estado no Brasil, tanto nas disposições do capítulo específico, art. 182 e 183, que trata especificamente da Política Urbana, quanto em outros pontos, como quando trata das regras de competência e dos Municípios. Aqui interessa os instrumentos - considerados por este trabalho como tradicionais - para planejar, gerir e disciplinar a atividade urbanística.

O instrumento chave para efeito de planejamento é o Plano Diretor, considerado pela Constituição, art. 182, § 10 como "instrumento básico da política de desenvolvimento e de expansão urbana". Seu conteúdo é complementado pelo Estatuto da Cidade, art. 40, que destaca o instrumento como "parte integrante do processo de planejamento municipal" devendo ser observado juntamente com o planejamento orçamentário; além de definir a abrangência de todo

\footnotetext{
${ }^{9}$ Autotutela está relacionado com a capacidade da administração pública agir, inclusive rever seus atos de maneira unilateral, independente de manifestação do poder judiciário. Consoante Enterría e Fernandez (2013, p. 554) "Ia administración está capacitada como sujeto de derecho para tutelar por si misma sus propias situaciones jurídicas, incluso sus pretensiones innovativas del status quo, eximiéndose de este modo e la necesidad, común a los demás sujetos, de recabar una tutela judicial".
} 
o território em suas previsões, e, sua revisão a cada dez anos. Estas questões, somadas as regras dos processo de elaboração, de obrigatoriedade, de conteúdo mínimo, entre outras previstas entre o art. 41 e 42-B, podem ser consideradas parte integrantes do regime jurídico das políticas públicas de planejamento urbano. O Estatuto da Cidade, destaca ainda, que em nível local, o planejamento urbanístico, além de estar integrar Plano Diretor e leis orçamentárias, deve atentar para: disciplina do parcelamento, do uso e da ocupação do solo; zoneamento ambiental; planos, programas e projetos setoriais; planos de desenvolvimento econômico e social.

A cadeia de instrumentos de planejamento urbano no direito brasileiro não se encerra na relação do Plano Diretor com as demais normas e políticas municipais. A Constituição Federal prevê no art. 21, IX, que compete a União, de forma exclusiva elaborar "planos nacionais e regionais de ordenação do território", que ainda não restam formulados. Outra alternativa, decorre do Estatuto da Metrópole, onde no art. 2으, VI, conceitua como "plano de desenvolvimento integrado", o instrumento que define "as diretrizes para o desenvolvimento territorial estratégico e os projetos estruturantes da região metropolitana e aglomeração urbana", estando seu regime jurídico previsto no art. 12 .

Assim, entre os instrumentos jurídicos tradicionais de planejamento urbano, podem ser indicados, entre outros: Os planos nacionais e regionais de ordenação do território, de competência federal; o plano de desenvolvimento integrado, que é de competência de uma instância interferderativa, devendo ser aprovado por lei estadual; e o Plano Diretor de competência local, juntamente com outros mecanismos. O próprio Estatuto da Cidade, no art. 4ㅇ, incisos I a III reforça esta visão múltipla de instrumentos, de responsabilidade de diferentes esferas de governo ${ }^{10}$. Tal realidade demonstra a relevância de observar-se as políticas públicas urbanísticas no contexto de complexidade sugerido até então: há uma série de normas materiais e formais, diversos centros de tomada de decisão e uma contingência de decisões políticas e jurídicas ocorrendo simultaneamente para que se exerça a atividade urbanística de planejamento.

Além do planejamento, o outro âmbito que compõe atividades urbanísticas é a gestão, que segundo Rubio (2009, p. 118), refere-se a execução do que foi planejado implicando na efetiva "transformación física (proyetos de urbanización y obras de urbanización) y jurídica (proyectos de

\footnotetext{
${ }^{10} \mathrm{O}$ art. 40, I a III do Estatuto da Cidade prevê: I - planos nacionais, regionais e estaduais de ordenação do território e de desenvolvimento econômico e social; II - planejamento das regiões metropolitanas, aglomerações urbanas e microrregiões; III - planejamento municipal, em especial: a) plano diretor; b) disciplina do parcelamento, do uso e da ocupação do solo; c) zoneamento ambiental; d) plano plurianual; e) diretrizes orçamentárias e orçamento anual; f) gestão orçamentária participativa; g) planos, programas e projetos setoriais; $\mathrm{h}$ ) planos de desenvolvimento econômico e social;
} 
equidistribuicion de benefícios y cargas del planeamiento mediante compensación y cooperación)". Ainda segundo o autor, a gestão está relacionada com "desde las circunstancias preexistentes al planeamiento a las necesidades previstas por la referida normativa incluida en los planes".

Note-se, deste modo, que as referidas atividades estão todas conectadas a espaços físicos. A 4a Revolução implica em uma digitalização dos espaços físicos. Canos, fios, ruas, quadras inteiras terão sensores. Sensores tanto que podem ser instalados pela Administração mas que também constarão nas estruturas particulares, e que conversarão entre si. Pela primeira vez, as intervenções urbanísticas poderão ser simuladas com dados efeituais, e acompanhadas em tempo real. Estes dados formarão um grande complexo que vai aumentar a quantidade de informação disponível para a Administração. Entretanto, mesmo com as novas e impressionantes ferramentas, os instrumentos de Direito Administrativo terão de se fazer presentes, já que a Política Pública implica uma intencionalidade e uma intervenção no mundo urbanístico: intervenção esta só possível com regulação, coerção, desapropriação e sanções. Não há como se ordenar (democraticamente) a cidade sem a participação de uma política urbanística. Mesmo em um futuro de edificações auto

A gestão envolve a construção de novos equipamentos públicos, estrutura viária, assim como, fornecimento de serviços públicos e a execução de outras tarefas práticas de materialização da atividade urbanística. Os instrumentos jurídicos utilizados para estas atividades tem um relação direta com o direito administrativo propriamente dito, por envolverem licitação e contratos administrativos, contratação de servidores, funcionamento de órgãos e prestação de serviços ao cidadão, que deve ter como enfoque o interesse público ${ }^{11}$, considerado de acordo com a programação do direito, em especial constitucional. Muitas vezes, as regras de gestão relacionadas com a prestação de serviços públicos estão previstas em leis que também irão tratar da disciplina.

Com último enfoque das atividades relacionadas ao urbanismo, está a disciplina urbanística, que consiste nas ações do Poder Público no intuito de garantir que o planejamento e a gestão sejam cumpridas. Tal ação está diretamente ligado ao exercício de poder de polícia e a emissão definitiva de autorizações, normalmente previstas nas legislações locais de parcelamento do solo, obras e posturas. Perante esta atividade, a questão da legalidade, conforme já trabalhado, ganha força na sua versão mais fechada, vez que a ação estatal acaba por condicionar direitos fundamentais, como propriedade, liberdade e livre iniciativa. Neste sentido, Carballal (2003, p. 255)

\footnotetext{
${ }^{11}$ O professor Arana-Muñoz (2014, p. 25) define que o interesse público "es en si mismo, en um concpeto susbstancialmente finalista" sendo princípio e fim. "Principio porque es presupuesto de su actuación. Y fin porque la Administración pública debe tender a satisfacer las exigencias del interés general de maner objetiva tal y como están conformadas el marco de los valores del estado social y democrático de derecho"
} 
destaca que "no le esta permitido al órgano municipal en ningún caso adoptar soluciones que prescindan de la legalidad vigente" vez que "Ia finalidad de las licencias urbanísticas no es otra que verificar la conformidad de lo que se solicita en la misma con el ordenamiento urbanístico aplicable", configurando-se assim, de natureza muito mais vinculante e do que discricionária.

Assim conclui-se o presente tópico, reforçando a visão complexa e aberta com que devem ser observadas as políticas públicas, vez que tratam-se de um acoplamento entre o sistema do direito e da política, cujo regime jurídico apresenta-se registrado prioritariamente na programação do direito em decorrência do acoplamento estrutural existente entre o direito e a política presente na constituição, que tem, entre outros desdobramentos, a formação de um regime jurídico calcado na legalidade.

Em relação aos instrumentos jurídicos que vão estruturar as políticas públicas que tratam da atividade urbanística, destacam-se, em termos de planejamento, o plano diretor e uma série de outros instrumentos setoriais em nível municipal, somado aos planos nacionais e regionais de ordenação do território, de competência federal, e o plano de desenvolvimento integrado, que compete a uma instância interfederativa e aos Estados Membros. Em relação a gestão urbanística, a atividade é prática, devendo ser normatizada pelos instrumentos e regime jurídico típicos de direito administrativo, muitas vezes, as normas estarão incluídas em instrumentos que também tem como enfoque a atividade de disciplina urbanística, tais como Código de Obras, de Posturas e Lei de Parcelamento de Solo.

Feita estas ponderações, cabe retomar o enfoque do texto para a questão das Smart Cities, no intuito de responder se estes instrumentos jurídicos tradicionais, que estruturam as políticas na emissão de decisões vinculantes para toda a sociedade, assim como, servem como programas para estabilizar expectativas normativas, mantém sua funcionalidade e relevância com o advento de novas tecnologias ou tendem a ser excluídos dando espaço a outros meios de ação governamental.

\section{Possibilidades Inteligentes para as Atividades Urbanísticas Tradicionais}

Apresentados os instrumentos jurídicos de planejamento, gestão e disciplina urbanística, passa-se a observar a relação da tecnologia com o exercício destas atividades. Para Baño Leon (2009, p. 104) o objeto da ordenação da atividade urbanística envolve, o solo, o subsolo e o espaço aéreo, este último, no que é relacionado ao limite de altura que as edificações podem possuir. Tal constatação do autor demonstra-se importante, vez que, as inovações decorrentes dos projetos de Smart Cities, embora em alguns casos sejam invisíveis aos olhos das pessoas, tendem a necessitar 
de a inclusão de diferentes infraestruturas que modificam o cenário urbano, seja no seu solo, subsolo ou espaço aéreo.

O primeiro ponto da análise toma como base o uso da tecnologia e o planejamento urbanístico. Para Rubio (2009, p. 105-106) "es en el referido aspecto del planeamiento como instrumento de diseño urbanístico donde el papel que pueden jugar las nuevas tecnologías tiene una mayor incidencia". Neste contexo, o autor destaca que a busca por informações fidedignas, sobre as reais necessidades de planejamento, se torna cada vez mais fácil por incidência das novas tecnologias "no siendo hoy pensable la realización de un plan general moderno sin la incorporación de una cartografia digital, de una base de datos y sistema de información geográfica".

A implementação de sistemas de informação já são hoje uma realidade no Brasil. O já extinto Ministério da Cidades, através do programa Capacidades, desenvolveu uma série de inciativas de capacitação neste sentido nas gestões municipais. A linha atuação do Programa, visava, entre outros aspectos, "apoio ao desenvolvimento institucional e à implantação de sistemas de informação nas administrações públicas". O resultado destas ações, somado as iniciativas locais, tornou comum acessar sites de Municípios brasileiros e ter acesso as informações gerais de desenvolvimento urbano local. Exemplos são encontrados desde grandes cidades, como São Paulo, através das consultas do mapa digital e do Datageo, até municípios médios, como Caxias do Sul-RS, com o sistema geocaxias. A dúvida que fica em aberto, cabendo uma pesquisa mais apurada, é saber se tais mudanças tem impactado na forma que se faz planejamento urbano e se, de fato, tais informações estão sendo direcionadas para esta finalidade.

Outro ponto fundamental é a relação da tecnologia com a chamada gestão democrática, que envolve a participação social no planejamento urbano. O Estatuto da Cidade, ao dispor sobre o regime jurídico do Plano Diretor, impôs a necessidade de seu processo legislativo contar, obrigatoriamente, como uma audiência pública. Seguindo a mesma lógica, o Estatuto da Metrópole, definiu que a criação do plano de desenvolvimento integrado, prevê a participação da sociedade civil organizada na seu processo de formulação. Ademais, Reck (2018a, p. 129) destaca que um dos programas gerais que compõe o regime jurídico das políticas públicas é a ideia de "gestão pública compartida" que define a necessidade das decisões públicas serem "compartilhadas com a comunidade mediante vários instrumentos", destacando para o uso tradicional das audiências públicas e reuniões de conselhos.

Neste ponto, já há alguns estudos que analisam a participação social através de tecnologias, como os apresentados por Guimarães e Araujo (2018) e Nabuco, Macedo e Ferreira (2009). As 
constatações sobre o uso das tecnologias para participação no planejamento de políticas públicas de urbanismo vão em dois sentidos: a um, que é um facilitador e aumenta a participação; a dois, que pode gerar uma exclusão social ainda maior, vez que nem toda população tem acesso a estrutura necessária, ou ainda, formação, para participar nos espaços digitais.

Ao lado do uso da tecnologia como forma de otimizar a informação facilitando e tornando mais eficientes as decisões relativas ao planejamento urbano, e de sistemas digitais para facilitar a participação da população nos processos decisórios de planejamento, há outro aspecto jurídico relevante neste âmbito, que trata das competências. Competência, neste trabalho é vista como "uma espécie de comunicação cuja função é estreitar o campo de decisões possíveis de determinados órgão", e, desta forma diminuir a hiperinformação, permitindo a especialização de cada unidade de tomada de decisão (RECK, 2018, p.63).

O uso da tecnologia no planejamento urbano no Brasil, hoje, está impactado por um problema de competência, visto que, boa parte das questões relacionadas a Smart Cities decorre de mecanismos relacionados a telefonia e energia, cuja competência extrapola o âmbito local. Tal pretexto tem sido usado por empresas que operam nestes ramos para questionar nos Tribunais as imposições contidas em normas de planejamento urbano. Desta fora, ainda que o governo local planeje uma cidade e decida por políticas públicas que vinculem a toda coletividade, estando previamente atento para as mudanças decorrentes das Cidades Inteligentes, podem tais modificações não serem aceitas como pelo no sistema do direito, pois não convergem com a programação que trata das competências.

Um exemplo são as decisões proferidas no processo do ARE 764029/RJ, julgado em 2018 no STF. Na ação, a empresa Light Serviços de Eletricidade S/A questiona a competência do Rio de Janeiro em estipular a instalação de fios subterrâneos, arguindo que se trataria de uma invasão do governo municipal em relação jurídica federal. No julgamento da AC 3420 MC/RJ, que visava dar efeito suspensivo ao Recurso, em sede de liminar, a Ministra Carmem Lúcia dispôs ter "como plausível que o legislador municipal tenha interferido nas condições estabelecidas entre a União Federal e a concessionária de serviço público". O argumento também destacou que a imposição das normas locais, poderia afetar o "equilíbrio econômico e financeiro do contato administrativo, em contrariedade ao art. 37, inc. XXI, da Constituição da República, o que impõe exame aprofundado e prioritário da matéria".

No julgamento do recurso, também em decisão monocrática, o Ministro Ricardo Lewandowski negou seguimento a matéria, definindo que a controvérsia se trata de ofensa indireta 
a Constituição (Súmula 280/STF), e ainda, de maneira genérica que "aos municípios legislar sobre assuntos de interesse local, respeitada a legislação federal e estadual", não entrando em definitivo no mérito da questão, permanecendo uma certa possibilidade variação, vez que há um indicativo de posições distintas dos Ministros do STF sobre o tema.

A própria redação da lei que regulamenta tal situação, art. 74 da Lei n. 9.472/1997, deixa em aberto algumas interpretações, ao aduzir: "A concessão, permissão ou autorização de serviço de telecomunicações não isenta a prestadora do atendimento às normas de engenharia e às leis municipais, estaduais ou distritais relativas à construção civil”. A dúvida é se os instrumentos jurídicos de planejamento urbano serão considerados como normas relativas a construção civil, ou, se não estão contemplados pela redação da lei federal.

De qualquer forma, como o sistema da política e o sistema do direito tem funções e códigos diferentes, o fato de existir uma controvérsia jurídica não deve ser um impeditivo para que as políticas públicas de planejamento urbanístico não atentem para o cenário das cidades inteligentes, trazendo para o seus instrumentos jurídicos, elementos que contribuam com uma certa estabilização neste sentido. Para Rubio $(2009$, p. 113) cabe as normativas urbanísticas "obligar al estabelecimento de las citadas infraestructuras de las $T I C^{\prime \prime}$ e a ainda, definir condicionantes de ordem estética, em decorrência que tais serviços são prestados por diferentes companhias, cada qual com sua estrutura, como acontece no Brasil ${ }^{12}$.

Relacionados alguns aspectos sobre o planejamento urbanístico e as novas tecnologias, passa-se a tratar dos instrumentos jurídicos de gestão do urbanismo, no âmbito das cidades inteligentes. Em termos de gestão, não há normas jurídica específicas, como no caso do planejamento e sua abordagem pode ser dividia em dois grupos: a implementação de obras de infraestrutura, materializando as propostas urbanísticas dos planos, e, a prestação de serviços públicos de atendimento ao cidadão. A primeira, envolve questões jurídicas relacionadas a previsão orçamentária, licitação, contratos administrativos, desapropriação, entre outras. A segunda, aos processos de aprovação de novas edificações e loteamentos, entre outros serviços, normalmente previstos nas leis de parcelamento de solo, códigos de obras e posturas. Nestes casos, entende-se

\footnotetext{
${ }^{12}$ A título de exemplo, na Espanha, já há legislações que exigem que as edificações devem possuir infraestruturas comuns para acesso de telecomunicação e tecnologias de informação, assim como, previsões de que os planos gerais devem conter normas específicas sobre o traçado das redes fundamentais de água, esgoto, energia elétrica, telefonia e demais serviços. Segundo Rubio "dentro de la intepretación extensiva y lógica para el servicio telefónico y de las determinaciones anteriormente señaladas de acesso obligatorio a las telecomunicaciones, debemos contemplar que los citados servicios incluyen es obligación de las infraestructuras de las TIC" (RUBIO, 2009, p. 110-111)
} 
que a gestão relaciona-se com o processo de aprovação, estando a emissão das licenças e a fiscalização, que também estão previstas nas citadas normas, no âmbito da disciplina, que será vista ao final do tópico.

Importante destacar que alocar recursos públicos na implementação do planejamento urbano, independente do debate sobre o uso de tecnologias, sempre apresentou-se como um problema. Vanin $(2015$, p. 152$)$ retrata a realidade dos governos locais no Brasil no período pós Constituição de 1988, onde há um aumento de atribuições em escala muito mais significativa que o complemento da receita, o que ocasionou uma dificuldade permanente dos entes locais para investir em infraestrutura urbana. Segundo Rubio (2009, p. 118) o debate da gestão urbanística das Smartie Cities tem como um dos principais desafios a "incorporación de los costes de urbanización de las obras de implantación de servicios de la sociedad de la información".

Observando-se a programação do direito no brasil, verifica-se que, com o advento da Lei n. 13.116/2015, que alterou a redação do já citado art. 72 da Lei n. 9.472/1997, esta questão restou ainda mais complexa e aberta. Na redação original, o dispositivo era taxativo em determinar que a empresa prestadora de serviço tinha a responsabilidade de instalar de cabos e equipamentos, e tal responsabilidade foi excluída, quando da nova redação.

Tal situação se demonstra ainda mais grave, quando observada a partir das reflexões de Tejedor (2015, p. 29), que aponta a alocação de infraestrutura como a primeira etapa na implementação de um projeto de cidade inteligente, afirmando que: "La primera tarea que las ciudades deben acometer para convertirse en smart cities es crear un entorno con alta penetración de comunicaciones de banda ancha que den soporte a aplicaciones digitales". A autora destaca, que tal espaço inclui infraestrutura de banda larga, que combinem, por exemplo "cable, fibra óptica y redes inalámbricas y que ofrezcan conectividad a los ciudadanos, a las organizaciones y a las empresas de la ciudad"13.

O fato de possuir infraestrutura para que a cidade inteligente se comunique é ponto chave no processo, e desta forma, se faz necessário investir neste sentido, ficando em aberto quem deve arcar com tal operação. Ojeda (2017, p. 82) destaca que, além das necessidades de arcar com a infraestrutura, há uma preocupação de gestão posterior que se relaciona a "mantener los servicios

\footnotetext{
${ }^{13}$ Acerca da complexa gama de infraestructura, cabe complementar a ideia da autora: "Además, es necesario crear entornos de espacios e infraestructura urbana con sistemas embebidos, dispositivos inteligentes, sensores y automatismos que ofrezcan gestión de datos en tiempo real, alarmas, capacidad de capturar y procesar la información generada y aplicaciones colaborativas basadas en la web que puedan recoger la inteligencia colectiva de los ciudadanos". (TEJEDOR, 2015, p. 29-30)
} 
en las debidas condiciones de adecuación y continuidad". Fica evidente o problema apontado por Rubio (2009, p.113), que ressalta a grande dificuldade da maioria dos municípios, frente aos altos custos de investimento e manutenção de infraestrutura para Smartie Cities ${ }^{14}$.

Os instrumentos de gestão urbanística de uma cidade inteligente necessitam estar atentos para esta realidade. Entre as possibilidades para que o custo não recaia integramente sobre a municipalidade, pode ser uma especificação dos planos, exigindo do particular, que no exercício do seu direito de construir ou de usar e parcelar o solo proceda "una serie de instalaciones que el proyecto de urbanización há de incorporar". Tal opção aponta para duas ressalvas: (1) inviabilização económica da iniciativa privada ${ }^{15}$; (2) natureza jurídica de determinadas redes, onde não há clareza se tratam-se de estruturas públicas ou privadas (RUBIO, 2009, p. 113).

Tais constatações tornam extremamente sensível o tema da gestão urbanística frente a tecnologia, no que diz respeito a implementação de políticas públicas para cidades inteligentes. Observar a promoção de infraestrutura como um gatilho para que políticas públicas de cidade inteligente possa ocorrer, sugere pensar para além do questionamento se os instrumentos jurídicos tradicionais deixaram de existir. Abre espaço para a perguntar se as cidades é que se tornarão obsoletas em seus processos de planejamento e gestão urbana, em decorrência de uma impossibilidade de investimento em novas estruturas tecnológicas ou na ausência de plano que supra esta lacuna, colocando em cheque toda a questão das Smart Cities no Brasil.

Muito menos controverso que a gestão relacionada a implantação das obras de infraestrutura, está a gestão urbanística relacionada aos serviços públicos de atendimento ao cidadão, que ocorrem por mecanismos denominados de e-GOV. Primeiro, pois não demandam de investimento tão significativo de recursos públicos; e, segundo, pois se trata de uma ação tipicamente do governo local, não se apresentando, por hora, um conflito de competência, nem uma possibilidade/interesse da ação privada na execução da tarefa. Apesar das hipotéticas facilidades, existem muitas críticas pela ausência de eficiência dos governos nas execução de tais tarefas. Um estudo da CBIC, que mediu o impacto da burocracia no imóvel, indica os serviços de aprovação como um dos principais gargalos. Neste contexto, já exemplos de utilização de tecnologia em ações que funcionam em municípios como Recife (Portal do Licenciamento), Porto

\footnotetext{
${ }^{14}$ Segundo o autor, "el enorme coste de las galerias de servicios comunales para estas infraestructuras de telecomunicaciones hace que dificilmente la totalidade de los ayuntamientos puedan estabelecer estas obligaciones".

${ }^{15}$ Rubio (2009, p.113) destaca que "el cumplimento práctico de las citadas especificaciones son difícilmente viables, por el enorme coste que repercute sobre la organización"
} 
Alegre (EdificaPoa) e Caxias do Sul (SMUWeb). São modelos que se valem da tecnologia para melhorar os resultados e a transparência dos serviços de gestão urbanística prestados diretamente para a população.

Como último enfoque na abordagem do uso de tecnologia voltado para o exercício de políticas públicas nas atividades urbanísticas, apresenta-se a questão da disciplina. A disciplina tem relação com o exercício de atividades típicas do Estado, consistindo nas decisões de regulamentar, autorizar, fiscalizar, penalizar, estando, em regra geral, prevista nas leis locais de parcelamento de solo, obras e posturas, que condicionam como o exercício de direitos do cidadão deve ocorrer naquele determinado território.

O autor Rubio (2009, p. 120-121) identifica um triplo plano na relação entre TICs e a atividade de disciplina urbanística, que evolve a definição de três tipos de regras: (1) de instalação, que visa autorizar as estruturas necessárias para dar sustentação ao modelo de Smart Cities, mediante regras processuais para aprovação arquitetônica e licença de instalação; (2) de funcionamento, visando regulamentar materialmente questões estéticas, modelo, horários de funcionamento, assim como os prazos a serem observados renovação; (3) de fiscalização - garantir que a permanência das estruturas observe os critérios de legalidade aferidos nas indicações anteriores.

O uso de tecnologia com a finalidade da disciplina urbanístico pode ser utilizado de diferentes maneiras: como forma de buscar-se indicadores de qualidade urbanística, como por exemplo, aferição de questões ambientais de qualidade de água e sonora, ou ainda, movimentação fluxo de veículos, com o intuito de direcionar as ações fiscalizatórias e políticas preventivas, como explicitado por Guitérrez (2017, p. 70), ao dispor que "las legislaciones urbanísticas deberían regular y se conecedoras de las pontencialidades de los modelos de gestión de smart city" potencializando que as premissas dos planos se materializem.

Apresentadas algumas soluções caracterizadas como inteligentes que podem ser utilizadas para a realização as atividades urbanísticas tradicionais de planejamento urbano, assim como, alguns de seus impactos e problemáticas jurídicas, cabe adentrar nas reflexões sobre o futuro dos instrumentos jurídicos utilizados até então para realização destas ações, respondendo ao problema quanto a possibilidade de sua obsolescência frente ao cenário das cidades inteligentes.

\section{Os Instrumentos Jurídicos Tradicionais no Contexto das Cidades Inteligentes}


O caminho até aqui traçado, que indicou elementos centrais das cidades inteligentes, pontou aspectos teóricos para a observação dos instrumentos jurídicos frentes as políticas públicas, descreveu quais são os principais mecanismos e a como a tecnologia tem afetado nos seus processos, com a indicação de algumas problemáticas e desafios já é suficiente para reforçar parte da hipótese inicialmente proposta: de que tecnologias não substituem os instrumentos jurídicos tradicionais, mas tendem a modificar o seu processo, com aumento da efetividade.

Tal constatação toma como base o fato de que, pelos estudos aqui apresentados, o território e as pessoas permanecem como os elementos centrais das atividades urbanísticas, sendo clara a necessidade de uma ação estatal, ainda que eventualmente em cooperação privada. As tecnologias, ao menos por enquanto, são apresentadas em um sentido de apoio ao exercício tradicional de tomada de decisão para políticas públicas direcionadas para o planejamento, a gestão e a disciplina urbanística e não a sua substituição.

A possível precipitação na apresentação da conclusão tem relação pela forma como as políticas públicas foram abordadas neste trabalho: tomando-se como base um cenário de complexidade e contingencia, que observou o tema das Smart Cities, a partir de categorias jurídicas evitam uma lógica mecanicista e fragmentada e apontam para uma visão ampla e aberta. A conclusão deve ser vista como algo parcial, resultado do conjunto das escolhas e do conjunto de observações aqui desenvolvidas, mas atenta para o fato de que existe uma série de outras variáveis que podem apontar para diferentes caminhos.

A conclusão decorre da forma como Reck e Bitencourt (2016, p. 135), observam as Políticas Públicas, ligando-as ao que dispõe o conteúdo dos "objetivos do Estado e da sociedade, uma vez que é a partir desses campos que as políticas públicas adquirem "vida", como resultado da própria política, do exercício do dever estatal", definindo que as ações de governo "somente podem ser compreendidas à luz das instituições e dos processos políticos que estão diretamente ligados com os interesses sociais". Tais concepções reforçam uma tendência apenas de mudança, mas não de abandono dos mecanismos tradicionais, visto que eles são baseados na concretização do texto constitucional, questão que não pode ser alterada pela simples implementação de novas tecnologias.

Por outro lado, há uma série de elementos intermediários que permanecem em aberto, quando observa-se os instrumentos jurídicos tradicionais, no âmbito da cidades inteligentes. As mudanças tecnológicas se apresentam em uma velocidade com um fluxo informacional muito distinto daquele que se tinha quando da concepção dos instrumentos. A previsão de uma revisão 
de Plano Diretor a cada dez anos, ou, a imposição de uma audiência pública em seu processo legislativo, por exemplo, parecem regras especificas que podem tornar-se - ou já são - obsoletas neste novo contexto tecnológico.

Neste tema, demonstra-se claramente presente a questão das "causalidades generativas", que, segundo Reck e Bittencourt (2016, p. 141) ocorrem pois "as políticas públicas, enquanto sistemas, alteram o seu ambiente, e essas alterações fazem com que os pressupostos de planejamento da política pública mudem". Em outras palavras: a realização políticas públicas voltadas a cidades inteligentes, com implementação de novas tecnologias, podem fazer como que os instrumentos jurídicos tradicionais, hoje ainda indispensáveis, tornarem-se desnecessários, inclusive para o alcance dos objetivos constitucionais. Neste sentido, demostra-se relevante a explicação de Rubio (2009, p 105), que destaca a necessidade da observância do tema, para além dos campos tradicionais:

Por tanto, dentro de un análisis de los aspectos más destacables de la incidencia de las nuevas tecnologías sobre el urbanismo deberemos de no sólo tener en cuenta las repercusiones sobre las tres grandes parcelas en que históricamente se ha dividido la regulación de dicha materia (planeamiento, gestión y disciplina) sino que deberemos integrarlo dentro del conjunto de cambios a que las ciudades $y$ poblaciones en general afrontan las variaciones del ámbito de convivencias y sus estructuras en virtud de dichas actuaciones.

Com a reflexão do autor, a própria divisão, amplamente utilizada neste trabalho, com efeito de organização do texto, dividindo as atividades urbanísticas em três grupos, que tratam do planejamento, da gestão e da disciplina, deve ser observada com ampla cautela, sem ser tomada como algo estanque, que signifique etapas subsequentes que devem ser observadas em ordem para produzir uma política pública. Muitas vezes sua observância desta maneira fragmentada é que acaba por ocasionar uma setorização da administração pública. Carvalho Pinto $(2005$, p. 72$)$ ao destaca que um dos problemas provenientes das estruturas administrativas de desenvolvimento urbano decorre do fato de que "cada órgão é avaliado segundo suas realizações setoriais e não há incentivos para uma cooperação ou articulação que implique o sacrifício de suas metas específicas em nome de uma racionalidade mais ampla".

Os instrumentos jurídicos com enfoque em políticas públicas para planejar, gerir e disciplinar as cidades inteligentes necessitam estar atentos a tais problemas, sendo uma alternativa a superação da noção tradicional setorizada pela visão de "gestão em rede", que traz consigo uma noção de cooperação onde os envolvidos atuem com foco em um objetivo comum. Também auxilia nesta reflexão, a ideia de "autonomia dependente", onde é ressaltado que "os gestores que 
planejam e acompanham as políticas públicas precisam entender que sempre os órgãos terão uma dinâmica própria", sendo assim, uma política pública necessita de ações entrelaçadas de cada um destes órgãos, sendo necessário que "planejamento e o acompanhamento das políticas públicas" tenham atenção a esta realidade e respeitem a "autonomia e o modo de operação de cada um dos órgãos da rede". (RECK; BINTERNCOURT, 2016, p. 144-146).

Tais observações, como gestão em rede e autonomia dependente, são essenciais para o enfrentamento dos desafios de planejamento urbano para cidades inteligentes: tanto na coordenação dos diversos tipos de planos, com competências de todos os entes federativos; quanto no debate sobre a quem cabe definir os critérios técnicos, estéticos e estruturais que serão observados quando da implantação das infraestruturas de tecnologia de informação. No campo da gestão das cidades inteligentes, as reflexões são válidas tanto para avaliar a cadeia de decisões que devem ser tomadas na execução de obras, quanto na prestação de serviços, que muitas vezes necessita uma comunicação entre órgãos dentro de uma mesma entidade ou de diversas esferas federativas. Na questão da disciplina, com o intuito de otimizar a ação concreta do Estado, evitando sobreposição em atividades fiscalizatória ou contradições na emissão de licenças necessária na implantação dos sistemas de Smart Cities.

Outro ponto chave nesta construção é a ideia noção de "policompetencia". Como ficou constatado na abordagem, as atividades relacionadas ao uso de tecnologia nas cidades podem redundar em diferentes áreas, cada qual, com um regime de competência específico: setores como meio ambiente, mobilidade, saúde, lazer, entre outras, tendem a ser afetadas quando da utilização de tecnologia em atividades urbanísticas. Assim, consoante disposto por Reck e Bittencourt (2016, p. 143) o critério pressupõe "o abandono do ideal de especialização absoluta", devendo as políticas públicas com enfoque em planejar, gerir e disciplinar as atividades urbanísticas das Smart Cities serem "flexíveis e contar com mecanismos tais que permitam lidar com mais de uma competência social".

No que diz respeito a comunicação entre as atividades de planejamento e de disciplina urbanística, também há uma questão em aberto, que não resta sanada com o uso da tecnologia. Normalmente, a programação prevista nas normas de parcelamento do solo, obras e posturas, não tem ligação com os disposto nas normas de planejamento, fazendo com que, o que se exija no exercício disciplinar, não tenha correlação com o que foi desenvolvido na atividade planejadora. Tal situação é indica por Vanin (2015, p. 128-129) como a necessidade de uma unidade substancial dos regramentos urbanísticos para garantir sua materialização. 
Quando trazido para o âmbito das cidades inteligentes, tais constatações podem ser observadas da seguinte maneira: as regras de instalação, funcionamento e fiscalização das estruturas necessitam possuir previsões nas leis que permitem uma ação mais concreta da administração pública, que inclusive, possibilitem o exercício do poder administrativo de polícia, não devendo estar previstas somente em normas de planejamento, como o Plano Diretor. Esta constatação, somada a comunicação entre direito e política, traz consigo a questão dos programas condicionais e finalísticos, trabalhados na teoria dos sistemas.

Luhmann (2016, p. 259-260) destaca que o direito "não pode levar em conta uma programação orientada para fins", e, apesar de tais situações ocorrerem no sistema, ele deve contar com programas condicionais para sua operação. Um programas condicional "estabelece as condições das quais depende se algo é legal (ou ilegal): com essas condições, faz referência a fatos passados, atualmente verificáveis", como ocorre nas definições dos tipos administrativos previstos nas normas municipais citadas.

Por outro lado, Luhmann (2016, p. 270) destaca que "a fixação do direito em programas condicionais de algum modo exclui que programa finalistas de outros sistemas funcionais se remetam ao direito", como ocorre com "os programas fins da política que remeta ao direito constitucional", entre os quais, as definições acerca da Política Urbana. O que se quer dizer, especificamente é que a existência de normas na modalidade de "objetivos" ou "diretrizes" servem muito mais para a operação da política do que para o direito, que necessita de programas condicionais para operar e cumprir sua função. Assim, não basta um elenco de valores, diretrizes, objetivos ou intenções que apontem para políticas públicas com enforque em cidades inteligentes: para o direito operar, se faz necessário a presença de programas condição que aumentem a possibilidade de operação do direito.

Para que o direito possa contribuir com a política no alcance de tais pretensões, se faz necessários, em complemento aos programas finalísticos, a existência de programas condicionais, aptos para a operação do sistema em um caso concreto. Neste sentido, Luhmann (2016, p. 271) destaca que "o entrejogo de programas fins e programas condicionais é frutífero", sendo indispensável nesta construção "que os sistemas e os tipos de programas se mantenham separados, e só por isso se podem esperar resultados".

Ademais, tratar de tecnologias aplicadas as políticas públicas com enforque em atividades urbanísticas é desenvolver o que Reck e Bitencourt (2016, p. 147) denominam de "interações não lineares". Envolve em "lidar com sistemas sociais altamente complexos e criativos, como a 
sociedade" e assim "admitir que os resultados podem ser imprevisíveis" ou, ainda "que há possibilidade de dois ou mais resultados possíveis". A tecnologia, pelo que foi visto até aqui tende a ser um apoio para um avanço nos instrumentos jurídicos que regulamentam as políticas pública de planejamento, gestão e disciplina urbanísticas, tornando-os mais efetivos. Entretanto, importante deixar claro, que isso permanece como hipótese pois, sua implementação pode gerar outro resultado, como ocorre no uso de sistemas digitais para participação social: altamente usuais e práticos para ouvir a população ao formular o planejamento urbano, sendo criadas para aumentar a influência da população nos processos, podem elas, ser o motivo de severa exclusão nesta mesma participação.

Em resposta ao problema, o trabalho constatou que tecnologia não apresenta-se, até então, como um substitutivo na utilização dos instrumentos jurídicos tradicionais para políticas públicas de planejamento, gestão e disciplina urbanística, apesar de apresentar uma série de funcionalidades que facilitam e otimizem a suas funções, sendo importante o avanço das reflexões e das experiências, com enfoque na consecução preceitos constitucionais, para que as tecnologias sejam um meio para melhorar a vida das pessoas nas cidades, proporcionando uma melhor prestação de serviços públicos e avanços nas condições econômicas e socioambientais da população em geral.

\section{Considerações Finais}

As políticas públicas de cidade inteligente são um dos resultados do processo de inovação que pode ser simbolizado pelas atividades desenvolvidas nas "Tecnópolis", fenômeno que motiva diversos países a buscar uma alteração do seu modelo industrial clássico, assim como, a incentivar que as cidades se utilizem dos TICs para uma maior eficiência das atividades desenvolvidas no espaço urbano, questão que já é pauta nos debates das agências internacionais e gera diversas repercussões no direito, entre as quais, possiblidade de inovação dos instrumentos jurídicos tradicionais voltados para o exercício de atividades urbanísticas.

Observar as políticas públicas neste cenário é visualizar algo complexo, sendo a teoria do sistemas um repertório conceitual apto na construção de reflexões que envolvem tomadas de decisões com reflexos nos sistemas da política e do direito. A utilização de tecnologia em políticas públicas de Smart Cities repercutirá de maneira diferente em cada um dos campos jurídico e político, por um lado visando estabilizar expectativas normativas, e por outro, com o objetivo de tomar decisões que vinculem a sociedade. 
No exercício destas funções básicas dos sistemas da política e do direito, os instrumentos jurídicos tradicionais que visam regular as atividades de planejamento, gestão e disciplina urbanística tem sido influenciados pelas novas tecnologias, já existindo inúmeros exemplos de experiências que facilitam a organização de dados sobre o território, tornam mais simples a participação das pessoas nos processos decisórios, ou ainda, mais transparentes e eficientes os serviços públicos urbanísticos prestados.

Apesar desta constatação, não se visualiza, até então, possíveis substitutos tecnológicos aos instrumentos jurídicos tradicionais que programam as políticas públicas de planejamento, gestão e disciplina urbanísticas, vez que, a utilização dos novos mecanismos de cidades inteligentes, tem sido utilizados como apoio para melhorar a efetividades dos instrumentos já existentes. De qualquer forma, fica a ressalva de que se trata de um tema em aberto, complexo e situado em uma realidade de contingência, sendo necessário destacar que o dinamismo da tecnologia tende a produzir resultados que podem ser imprevisíveis, ou mesmo, que avanço do uso da tecnologia como apoio seja suficientemente capaz de substituir os instrumentos hoje existentes no direito.

\section{Referências}

ARANA MUÑOZ, Jaime Rodrígues. Derecho Administrativo y Administración Pública en Tiempos de Crisis. Caracas: editorial jurídica venezolana, 2014.

BAÑO LEON, José Maria. Derecho Urbanistico Común. Yustel: Madrid, 2009.

BRASIL. Constituição Federal. Disponível em https://bit.ly/1blJ9XW. Acesso em 30.12.2018.

BRASIL. Capacidades: Programa Nacional de Capacitação de Cidades. Disponível em https://bit.ly/2RJ7Ukt. Aceso em 08.01.2018.

BRASIL. Estatuto da Cidade. Lei 10.257 de 10 de julho de 2001. Regulamenta os arts. 182 e 183 da Constituição Federal, estabelece diretrizes gerais da política urbana e dá outras providências. Disponível em https://bit.ly/106qbRX. Acesso em 31.12.2018.

BRASIL. Estatuto da Metrópole. Lei n. 13.089 de 12 de janeiro de 2015. Disponível em https://bit.ly/1bxHRE7. Acesso em 08.01.2019.

BRASIL. Estratégia Nacional de Ciência, Tecnologia e Inovação 2016-2022. Brasília: Ministério da Ciência, Tecnologia, Inovações e Comunicações, 2017.

BRASIL. Lei n. 9.472 de 16 de julho de 1997. Dispõe sobre a organização dos serviços de telecomunicações, a criação e funcionamento de um órgão regulador e outros aspectos institucionais. Disponível em https://bit.ly/2Rsej4b. Acesso em 07.01.2019.

BRASIL. Lei n. 13.116 de 20 de Abril de 2015. Estabelece normas gerais para implantação e compartilhamento da infraestrutura de telecomunicações. Disponível em https://bit.ly/2FxBqD7. Acesso em 07.01.2019.

CBIC. O Custo da Burocracia no Imóvel. Disponível em https://bit.ly/2sjuCRQ. Acesso em 09.01.2018.

CARVALHO PINTO, Victor. Direito Urbanístico: Plano Diretor e Direito de Propriedade. São Paulo: Revista dos Tribunais, 2005.

CARBALLAL, Almudena Fernández. Derecho Urbanísitico de Galícia. Civitas: Madrid, 2003. 
CASTELLS, Manuel; HALL, Peter. Tecnópolis del mundo: La formación de los complejos industriales de siglo XXI. Madrid: Alianza Editorial, 2001.

ESPANHA. Plan Nacional de Ciudades Inteligentes. Madrid: Gobierno de España, 2015. Disponível em https://bit.ly/2d00Wkb. Acesso em 29.12.2018.

GARCÍA DE ENTERRIA, Eduardo. FERNANDEZ, Tomáz-Ramón. Curso de Derecho Administrativo I. 16a ed. Pamplona: Civitas, 2013.

GUIMARÃES, Patrícia Borba Vilar; ARAÚJO, Douglas da Silva. 0 direito à cidade no contexto das smarts cities: o uso das tic's na promoção do planejamento urbano inclusivo no Brasil. Revista de Direito da Cidade, v. 10, n. 3, p. 1788-1812, ago. 2018.

GUIMARÃES, Patrícia Borba Vilar; XAVIER, Yanko Marcius de Alencar. Smart cities e direito: conceitos e parâmetros de investigação da governança urbana contemporânea. Revista de Direito da Cidade, v. 8, n. 4, p. 1362-1380, dez. 2016.

GUITÉRREZ, Rubén Martinez. El Impacto de las Smart Cities en La Tuetela Ambiental y en la Planificación Urbana. p. 53-73. In MAÑAS, José Luis Piñar; OJEDA, Magdalena, Suárez. Smart Cities: Dereho y Técnica para Una Ciudad Más Habitable. Madrid: Réus, 2017.

LUHMANN, Niklas. O Direito da Sociedade. São Paulo: Martins Fontes, 2016.

MAÑAS, José Luis Piñar; OJEDA, Magdalena, Suárez. Smart Cities: Dereho y Técnica para Una Ciudad Más Habitable. Madrid: Reus, 2017.

MATEO, Ramón Martín; SANCHEZ, Juan José Díez Sánchez. Manual de Derecho Administrativo. 29a ed. Pamplona: Aranzadi, 2012.

NABUCO, Ana Luiza; MACEDO, Ana Lúcia; FERREIRA, Rodrigo Nunes. A experiência do Orçamento Participativo Digital em Belo Horizonte: o uso das Novas Tecnologias no fortalecimento da Democracia Participativa. Revista IP - Informática Pública, Belo Horizonte, a. 11, v. 1, p. 139-155, 2009.

OJEDA, Magdalena, Suárez. Smart Cities: Un Nuevo reto para El Derecho Público. p. 73-92 In MAÑAS, José Luis Piñar; OJEDA, Magdalena, Suárez. Smart Cities: Dereho y Técnica para Una Ciudad Más Habitable. Madrid: Reus, 2017.

ONU. Documentos Temáticos Habitat III: 21-Cidades Inteligentes. Nova lorque: ONU, 2015. Disponível em https://bit.ly/2EZ8Av3. Acesso em 31.12.2018.

ONU. Nova Agenda Urbana. Quito: ONU, 2016. Disponível em https://bit.ly/2LGSCab. Acesso em 31.12.2018.

PIEKAS, Andrezza Aparecida Saraiva; BERNARDY, Rógis Juarez; SEHNEM, Simone; FABRIS, Juliana. Aspectos legais e percepções sobre as estratégias para cidades inteligentes e criativas: estudo da cidade de Chapecó (SC). Revista Brasileira de Gestão Urbana (Brazilian Journal of Urban Management), 10(Supl. 1), 197-211, 2018.

RECK, Janriê Rodrigues; BITENCOURT. Caroline Müller. Categorias de análise de políticas públicas e gestão complexa e sistêmica de políticas públicas. A\&C - Revista de Direito Administrativo \& Constitucional, Belo Horizonte, ano 16, n. 66, p. 131-151, out./dez, 2016.

RECK, Janriê Rodrigues. Observação Pragmático-Sistêmica da Personalização dos Entes Federativos e suas Competências em Políticas Públicas In BITENCOURT, Caroline Muller; RECK, Janriê Rodrigues. Políticas Públicas e Matriz Pragmático-sistêmica: os novos caminhos científicos do Direito Administrativo no Brasil. Santa Cruz do Sul: Essere Nel Mondo, 2018.

RECK, Janriê. Observação Pragmático-Sistêmica das Políticas Públicas e sua Relação com os Serviços Públicos In BITENCOURT, Caroline Muller; RECK, Janriê Rodrigues. Políticas Públicas e Matriz Pragmático-sistêmica: os novos caminhos científicos do Direito Administrativo no Brasil. Santa Cruz do Sul: Essere Nel Mondo, 2018a.

RUBIO, Fernando Garcia. Nuevos Retos Sectoriales del Urbanismo. La Ley: Madrid, 2009.

STF. Ação Cautelar AC/3.420. Relatora: Ministra Carmem Lucia, julgada em 05/08/2013. DJ 29/8/2013. Disponível em https://bit.ly/2Rsgpkz. Acesso em 08.01.2019. 
STF. Agravo em Recurso Extraordinário ARE 764.029/RJ. Relator: Ministro Ricardo Lewandowski, julgada em 08/05/2018. DJ 08/06/2018. Disponível em https://bit.ly/2Db9GCu. Acesso em 08.01.2019.

STRAPAZZON, Carlos Luiz. Convergência tecnológica nas políticas urbanas: pequenas e médias "cidades inteligentes". Convergência Tecnológica nas Políticas Urbanas. Curitiba, n. 22, Temática n. 6, p. 89-108, 2009.

TEJEDA, Nacís Vidal. Las Smart City: Las Ciudades Inteligentes del Futuro. Barcelona: UOC, 2015. VANIN, Fábio Scopel. Direito e Política Urbana: Gestão Municipal para a Sustentabilidade. Caxias do Sul: Educs, 2015.

Trabalho enviado em 22 de janeiro de 2019

Aceito em 20 de abril de 2020 